\title{
HYBRID GIS-BIM APPROACH FOR THE TORINO DIGITAL-TWIN: THE IMPLEMENTATION OF A FLOOR-LEVEL 3D CITY GEODATABASE
}

\author{
G. Sammartano ${ }^{\mathrm{ab}}$, M. Avena ${ }^{\mathrm{ab}}$, M. Cappellazzo ${ }^{\mathrm{ab}}$, A. Spanò ${ }^{\mathrm{ab}}$ \\ ${ }^{a}$ LabG4CH - Laboratory of Geomatics for Cultural Heritage. Department of Architecture and Design (DAD) - Politecnico di Torino \\ Viale Mattioli 39, 10125 Torino (Italy) \\ ${ }^{\mathrm{b}}$ Polito FULL | the Future Urban Legacy Lab, Toolbox coworking. Via Agostino da Montefeltro 2, 10125 Torino (Italy) \\ giulia.sammartano@polito.it; marco.avena@unito.it; antonia.spanò@polito.it; marco.cappellazzo@polito.it
}

Commission WG IV/9

KEY WORDS: 3D city model, urban analyses, digital twin, 3D cadastre, spatial data, floor modelling, multi-dimensional data

\begin{abstract}
:
The research tries to present a preliminary work into geo-spatial management of public administration assets thanks to interoperability of BIM-GIS models, related to urban scale scenarios. The strategy proposed tries to deepen the management, conversion and integration of databases related to public assets and particularly schools building, and related them into city-related geo-databases. The methodology, based on the real scenario of Torino Municipality and their needs addressed in recent studies in collaboration with FULL - Future Urban Legacy Lab from Politecnico di Torino, take advantage from the availability of two test dataset at different scale, with different potential and bottlenecks. The idea of developing a 3D digital twin of Torino actually stop long before the 3D city modelling only, but rather we have to deal with the integration and harmonization of existing databases. These data collections are often coming from different updating and based on non-homogeneous languages and data models. The data are often in table format and managed by different offices and as many management systems. Moreover, recently public administrations as the one of Torino, have increase availability of BIM models, especially for public assets, which need to be known, archived, and localized in a geographic dimension in order to benefit from the real strategic potential of a spatial-enabled facility management platform as Digital Twin. Combining the use of parametric modeler software (Revit) and visual programming language (Dynamo), the proposed methodology tries to elaborate rules on a set of shared language parameters (characterizing the buildings as attributes in both datasets: ID; address; construction; floors; rooms dimensions, use, floor; height; glass surfaces). This is tested as conversion workflow between the Municipality DB and the BIM model. This solution firstly allows the interaction and query between models, and then it proposes open issues once the enriched BIM model is imported into the geographical dimension of the Torino 3D city model Digital Twin (ArcGIS Pro platform), according to LOD standards, and enriched with semantic components from municipality DB
\end{abstract}

\section{INTRODUCTION}

The future of our cities increasingly depends on the ongoing implemented strategies to monitor, govern and forecast the complexity of human-related phenomena and urban regeneration, especially for brownfields and underuse, or building re-use and readaptation, especially public assets. The contribution of geospatial data science, applied since long time to the urban scale modelling, is currently moving toward many directions on supporting decision making through data collection, data visualization, 3D modelling and effectively twinning real word (Billen et al., 2014; Ruohomaki et al., 2018). In fact, the design of advanced platforms, with the help of support public governance with computer-based replicas able to twin the real world in adaptive 3D city models is now habit calling digital twins (Shahat et al., 2021) (DUET Project, EU, 2019)

They are expected in the next future to carry out not only data gathering, visualization, navigation, domain analysis (Biljecki et al., 2015; Billen et al., 2014), but also advanced big data analysis supporting correlation, updating, simulation and prediction of urban phenomena (Shahat et al., 2021). Particularly, the needs of urban design and urban morphology studies is to model the digital replicas with the joint purpose to store heterogeneous data but to effectively integrate information and promote spatial correlation of semantic data and support urban planning strategies too. Most effort in concretely achieving this idea that is fully active in current researches, beyond the informatic programming, the highperformance computing and the enhanced graphical rendering of these digital systems, should be directed to the managements of starting data, objects, repositories, different databases, languages in public administration. This goal is far from being achieved yet and the challenge requires us to test the strategies with real case studies as many cities are undertaking (Lehner \& Dorffner, 2020) and implements the research on replicable methodologies, common languages and standards updating.

Nevertheless, the purposes of integration for existing data making them efficiently used and different expert-related languages in favour of interoperability in public administration, is among the most pursued objectives, also and above all from a holistic and empirical point of view (Eriksson \& Harrie, 2021). Very often, municipalities offices have at their disposal a large amount of information, in terms of many different archives that have been conceived at different times and for different purposes too. The problem is not only the extension of archives indeed (that recently started to become digital) but their structure. The general design of the DB architectures, the nature of objects represented in the DB (ontological scheme), the data model and the relationships among information stored, the configuration of updating flows, metadata, etc. are crucial aspects and tasks that enable the good use of the archives.

Furthermore, it is essential to say that many archives and inventories are not spatially located, or else geo-coded and not consistently related to 2D/3D cartographic datasets. Many times it is possible to consider that if many information archives could be converted or merged with a spatial database, many benefits and advantages could come from those resources. An adaptation of spatial and non-spatial digital archives, in the direction of 
merging them, i.e. constructing relationship that enable spatial location of any information, offer the chance to enable more deepen comparison and interpretation of city phenomena and awareness about the distribution of its potential.

The perspective aimed at information managing best practice derived from archives connection and harmonization, which can be used as tools for basing a decision support framework.

These databases, technical-authorities, tax, estate, are often related to different temporal updating and based on nonhomogeneous languages and data models. The data archives are often in table format and managed by different offices and as many management systems. Moreover, recently public administrations have increasingly availability of BIM models, especially referring to public assets, which need to be known, archived, and localized in a spatial dimension in order to benefit from the real value of their gathering.

In this framework, the research tries to work in a preliminary direction toward exchange of data from multiple databases into geographical space, with BIM-GIS models related to urban scale scenarios. The strategy proposed tries to deepen the issues related to city-related databases available for the Torino Municipality and the Piemonte Region.

\subsection{Framework on indoor floor-level information}

The digital twin notion is nowadays ubiquitous while speaking about digital representation of the real cities, climate change forecasting, objects manufacturing, economic systems, even the earth (Batty, 2018; Bauer et al., 2021). A consistent number of researches and users explicitly mention semantic 3D digital models as representations of real-world entities.

Considering the idea of 3D metric replicas as proper prerequisites of modelling Digital Twins for our cities, the selection of standard approaches and common languages could represent for the future one of the most important characteristics to improve in undertaking this new era of 3D city models. But at the same times, it is true as well to promote simple and easily procedures, but applicable in generalized approaches for public administration (Eriksson \& Harrie, 2021). The possibility to benefit from a 3D enriched representation of human-related areas, especially cities, beyond the traditional $2 \mathrm{D} / 2.5 \mathrm{D}$ mapping point of view, is an essential starting point as well.

Surely the OGC CityGML standard defining data model applied to urban 3D modelling is an well-recognized starting point first of all in the design and conception of Level of Detail (LOD). It has been developed in its last revision for enlarged users, proposed in 2018 and formalized in (Kutzner et al., 2020), and the various specification proposed (Biljecki et al., 2016) with the new concept of human-related space. This could allow on the one hand, the required coherence between the replica and its real-world counterpart and its scalable information (Biljecki et al., 2016) and on the other, to plan and ensure continuous integrations and updates of semantic/geometric data into the model.

In parallel developments, the interest to indoor space definition has been increasing. Also the floor plans entities have been integrated in CityGML data model (Konde et al., 2018), retrieving the definition of floor-related information management from IFC standard and proposing a specification of LoD0.

In fact, in this high scale implementation perspective, the current research proposes also to relate the urban-scale standards as CityGML to the usual building-scale standard, as IFC., as countless experiences are demonstrating. The goal is mainly to re-define in a human-activity-based perspective the data model for the concept of indoor-outdoor spaces of CityGML standard (Tang et al., 2018). This proposal moves a little away from the only LoD4 in which it was considered the indoor space. This point of view, in fact, propose the conception of indoor-related data model along different level of detail specification from coarse to detailed (from ILoD0 to ILoD4), according to different semantic aspects increasing detailing the building model (structure, connectivity, and volume), and merging the concepts of indoorGML standard and mainly IFC standard, typically related to the building.

The conception of floor-related information is strictly connected also to the traditional cadastre domains, in which recent developments are directed toward the digitization and harmonization, 3D implementation and floors management information (Hagba et al., 2021). In particular, the management of cartographic objects most related to cadastral public-private parcels are closely associated to the indoor spaces and thus typically connected to the floor level (Konde et al., 2018; Lisec et al., 2017). Also in this sector, the linking between the GIS cartography SDI and the BIM world is increasingly topical and urgent, and interesting as well. Recent conception Urban BIM paradigms or GeoBIM systems are investigated to establish even stronger relation BIM models in urban word (Noardo et al., 2020).

In the prevision of these model for supporting morphological analysis and urban planning actions, the 3D data is not only a geometry feature but the punctual semantic content to the single floor, and then in perspective, even the single unit (e.g.: the vertical variability of the uses, real or planned) (Figure 1).

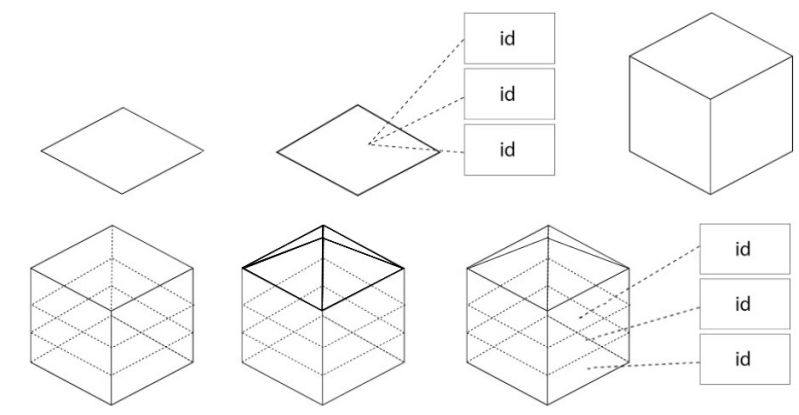

Figure 1. Schema on example of data relation from public real estate to the building units and to the floors levels.

\section{CASE STUDY: THE TORINO DIGITAL TWIN}

The case study we considered is the one of Turin municipality. The interest is due to the recent purposes of the city to trigger an analysis of the processes of decommissioning and obsolescence of the built heritage, in particular the management of the public one pertaining to the city, with the aim of reflecting on the intensity of use, the dynamics of transformation and potential of real estate. In fact, for the City of Turin and for modern metropolis, a better understanding of how heritage assets are distributed in relation to the current urban dynamics, is useful in the perspective of redefining the role of public buildings in different parts of the city, even before a specific enhancement strategy e regeneration. The availability of an advanced 3D representation of the city, in relation with such municipality management strategies, is a current debate topic shared and pushed forward with the experts of cities regeneration research too, involved in the FULL (Future Urban Legacies Lab), a new institution of Politecnico di Torino.

The public real estate assets of the city of Turin, including particular attention to public buildings, school buildings, public offices and administrative headquarters, are represented in alphanumeric databases. Two test datasets are at the research disposal, referring to two different scales.

- (I) The first test-dataset belongs to the facility management platform Factotum, which has been made available in the form of extracted datasheets. As mentioned, the inventory, having to support the management of public properties from the point of 
view of its maintenance, current expenses and rents, also stores information relating to the consistency, use and occupation of the real estate assets. The database objects of this first test can be real estate, plots of land and even simple real estate units within the property. The most easily to be reconstructed in a spatial reference connection is that of the cadastral spatial database. Consequently the minimum objects scale is the building unit into the parcel.

- (II) Among all the municipality properties, schools legacy had a special consideration also referring to the recent pandemic situation, which made urgent some reflections on the availability of spaces in school buildings to allow for the spacing increasing imposed by the new health regulations. Also the specific information about the school of Turin are stored in regional repository, made available by datasheets; that is EDISCO (EDIlizia SCOlastica) the second test dataset.

Starting from these different situations of data availability regarding the two test dataset, different geo-referencing strategies or possible linking into the spatial dimension with geometric entities of the digital cartography have been planned and achieved. Accordingly, we planned to carry out two different test of validation using two different types of test. First results and preliminary evaluations are referred below in this proposal.

\subsection{A point of view on schools system}

The schools infrastructure database is surely more complex and complete. Even though it concerns alphanumeric data and not using a cartographic definition, we can say that the scale of data is highest because information about dimensioning, characteristic, utilization of the school buildings spaces are provided arriving at the single rooms as minimum entity of the database. Other information about construction age, school grade, hosted students, etc are referred to the entire school. So the building and indoor-building dimension is the scale of this second test. In addition, public administration has available, and will always have more, a set of BIM models (by CSI Piemonte) for management of spaces, maintenance and consumption, at the moment, for a very small part of the public assets. High-detailed parametric models referring to schools buildings enriches the scale detail of the second dataset.

The three schools here used as a case study have been chosen because of their heterogeneity and the different built-in urban context. The Coppino primary school in the Crocetta district it's a rather old building (1903) that develops vertically and has exiguous open spaces, due to the dense urban context. The Deledda primary school, built in the Italian golden age of educational construction (1969), lay instead in an open building context and has at its disposal a large open space. Lately, the Rosa Luxemburg kindergarten is the most recent building (1974), placed in a rather free urban context, develops horizontally and is equipped with a large outdoor space (EDISCO DB).

\section{METHODOLOGY}

The proposed methodology is based on the real scenario of the presented Torino Municipality, that has been selected as case study to develop step by step in the next future the geometric and semantic content of a so-called digital twin. The starting interest, as introduced, is the possibility to actually relate in the 3D city models the public administration assets in the form of available information (datasheet, BIM) with the short- and long-term purposes to be geolocated, linked, integrated, explored and queried into a spatialenabled 3D database. The research try to considerate also the crucial chance of the updatability of the systems, in the direction of streamline the inventory, control and modification procedures.

Figure 2. The schema of the proposed methodology in Torino case, long before the design of the 3D city modelling itself, we have to deal with the issue of information organization and enrichment into geometric simplified objects, and we rather

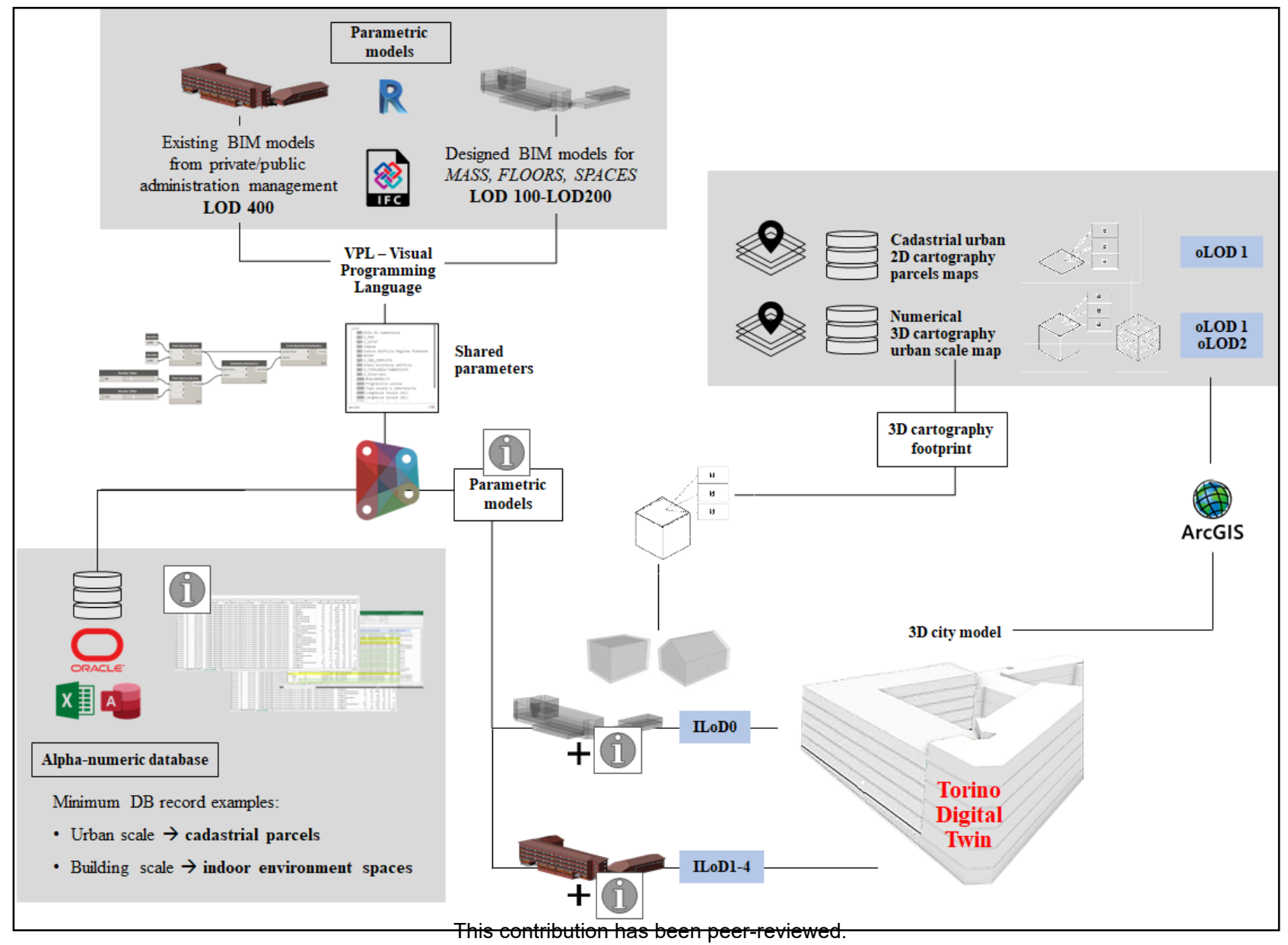


analyse the integration and harmonization of existing databases in order to work, in long-time perspective, to the conception of a 3D model actually twinning the city.

The research methodology firstly questioned several actual needs of the current case study, public building and particularly schools. First of all, providing a brief summary, the research planned to geolocate real estate data of public assets (I) and school-related information (II).

The geolocation required, for the first case, the buildings floors level, and the indoor spaces (room unit) for the second, making necessary the management of a 3D geodatabase. The proposed approach is clarified in Figure 2.

We initially generated this spatial resource reconstructing proper relationships linking objects of the alphanumeric tables to the related cadastral geometric feature class, wherever available, and consequently, to the urban technical map dataset corresponding to urban footprint feature class, storing physical characteristics of buildings including heights, elevation, floors number (see Par. 3.1).

Two questions remain open: the direct and coherent connection of alphanumeric DB into geometric objects, and management of indoor objects themselves, especially when originated from existing BIM objects. For the tasks, we initially searched for an experimentation of a straightforward pipeline for non-expert informatic programming and without the use of complex framework data models, at present. This has been accomplished combining the use of Dynamo visual programming interface for data transformation conversion and automatic connection (see Par. 3.2). The Dynamo pipeline organizes a set of parameters from the DB characterizing the buildings as attributes and directly connected with BIM structure (ID; address; construction; floors; rooms dimensions, use, floor; height; glass surfaces). The parametric objects generation (BIM models) hosting these added information from the DB by VPL conversion workflow are the starting objects, both in case of generated-from-scratch or exploiting the availability of existing BIM models. Secondly, the demand was how to interact with the enriched BIM model to query data related to the unitary elements inside the building (school example: rooms size, laboratories, gyms disposal, lecture halls, rooms).

Finally, the approach tries to verify if the enriched BIM models could be linked in the 3D GIS space, keeping the semantic content to be queried, ad geographical objects, in a transversal way, i.e. across distinct schools of course (see Par. 3.3).

\subsection{From LOD2 to floor-level implementation}

The 3D city model of Torino was designed starting from regional spatial data infrastructure and urban cartography. In fact, the organization of the data model starts form official data from the Torino Municipality (digital urban technical map, 1:000 scale), leading from LOD0 to LOD2 modeling according to City GML definition.

The availability of a LiDAR flight dated back to 2018 provided the elevation data to derive DSM and DTM and also height update and roofs shape. Current methodologies based on points clouds segmentation, labeling and classification (Rottensteiner et al., 2014) are available to derive 3D building reconstruction from LiDAR traditional data (Baltsavias, 1999), also exploiting oblique imagery (Nex et al., 2013) and DTM extraction from DSM by bare-earth and objects in urban scenario (Pfeifer \& I.P.F. Team, 2008; Sithole \& Vosselman, 2004)

The other available data were the rich technical map DB and cadastral parcels DB of the public assets of the city of Turin, and not least the DB relating to schools buildings, their spatial organization and functional management.

LoD0 model corresponds to: terrain

2 footprint (1:1000 scale, objects "unità volumetriche")

LoD1 refers to:

terrain

footprint $3 D$ extrusion according to building height (1:1000 scale, "unità volumetriche", attribute "ALTEZZA_VO”,"'QUOTA_SUOLO”,"QQUOTA_GRON DA")

LoD2 is generated form:

- terrain

- $\quad 3 D$ model extrusion with roofing shape characterization.

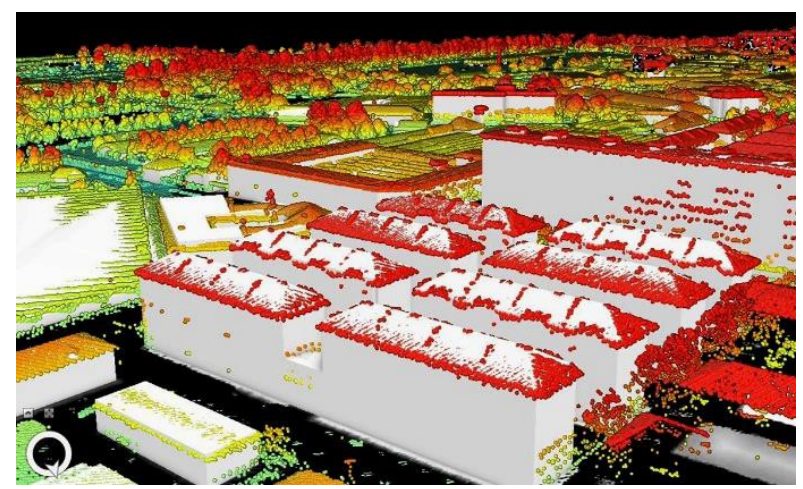

(a)

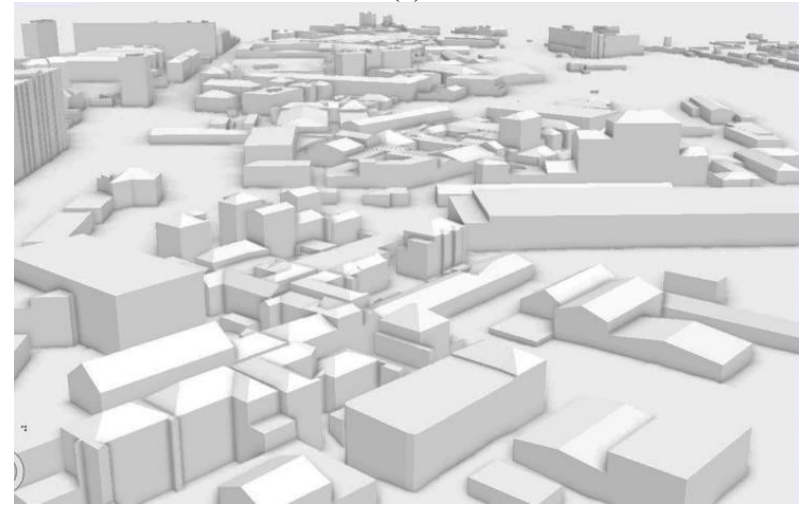

(b)

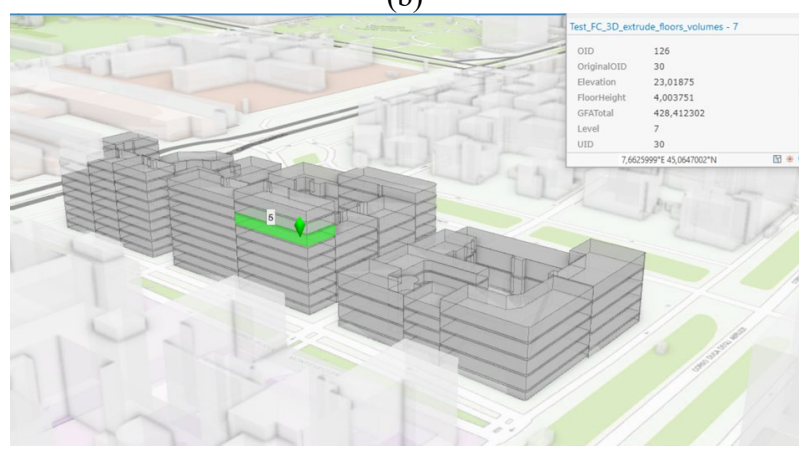

(c)

Figure 3. The Torino 3D city model structure: (a) LoD2 extraction from Lidar DSM; (b) LoD2 from footprint, height and roof shape; (c) floors elements definition

The methodology for the roof shape extraction and LoD2 model generation (Figure $3 \mathrm{a}, \mathrm{b}$ ) as presented in (Jayaraj \& Ramiya, 2018) is the use of starting geometry data as building footprint (extracted from municipality technical digital map of Turin city), and the LiDAR dataset, from which to derive:

- DTM, Digital Terrain Model, - DSM, Digital Surface Model,

- nDSM, Normalized Digital Surface Model (considering only the elevation of the features above ground). 
From an operative point of view, the ESRI ArcGIS Pro platforms, implementing the algorithm, have been used for the workflow development with creating 3D building, for roof form extraction. In the same system it is possible to split building into floors (Figure $3 \mathrm{c}$ ) using the information embedded into footprint attribute ("NUM_PIANI") In fact, an intermediate level of modeling is useful for floor-level information to be associated. Considering the definition of indoor information related to LoD4 and also the floor plans geometry in the definition of data model described in (Konde et al., 2018) as a variants of LoD0, we achieved a relatively simple geometry of exterior and floors to be connected to only to floor-scale information. In fact, for cadastral database, spatial location of single parcels on floors are not available in numeric form. Concerning other high-detail indoor information, the spatial position of rooms in school building instead, are available into BIM models. Both the cases of floor level modeling need to ben connected with the public assets DB and enriched of numerical and thematic information.

\subsection{BIM models enrichment}

The possibility to benefits from parametric BIM, as a base of intermediate object connected to the public DB, comes into play in this step, supporting the modelling of building scale components corresponding to LOD 100 and LOD200: mass + floors + spaces. Great attention should be paid to interoperability issues related to IFC-to-CityGML (Noardo et al., 2020).

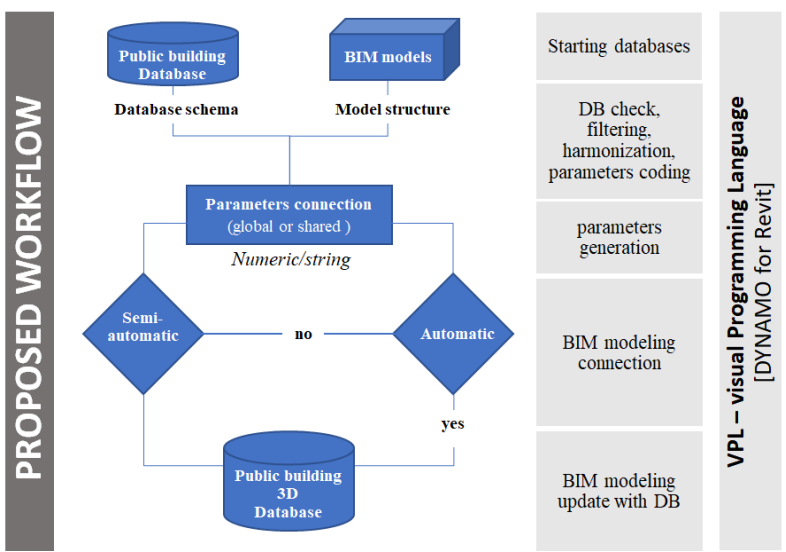

Figure 4. The synthetic proposed data flowing pipeline applying with VPL: from public DB and BIM models to 3D spatial database

The $1^{\text {st }}$ direction of the workflow plans not to have availability of starting BIM model of public buildings so, to generates from scratch parametric object corresponding to LOD 100-200 and to annotate them with floor-information-based $\mathrm{DB}$ (and then imported into the 3D city model in GeoDB). This is proposed for Dataset (I).

The $2^{\text {nd }}$ foreshadow the availability of already generated BIM model. This is proposed for Dataset (II). Often they are not harmonized with names and numbering from EDISCO DB and this bottlenecks does not help to generalize the applicability of the workflow. Specific reflections should be conducted in the future opportunity to control on BIM models generation of public assets, coherently with homogeneous languages and data models, to ensure that the information DB content connect with the spatial-geometry one. This is a fundamental prerequisite, of course. The enriched BIM model can migrate into the GIS space for validating visualization and information extraction.
The VPL-based rules have been proposed for checking the connection and translation of parametrization between public assets DB and schools data DB and geometries (cartographicbased or parametric-built), as proposed in Figure 4.

\subsubsection{Visual modelling tools for database flow into BIM}

Nowadays the integration of visual programming in enhancing data modeling and management, is significantly diffusive also in engineering or architectural design processes (Boshernitsan et al., 2004). In particular VPL - Visual Programming Language, largely exploit advanced functionalities for supporting modeling algorithms and specifically in VPL modelling software Grasshopper for Rhinoceros 3D and Dynamo for Revit.

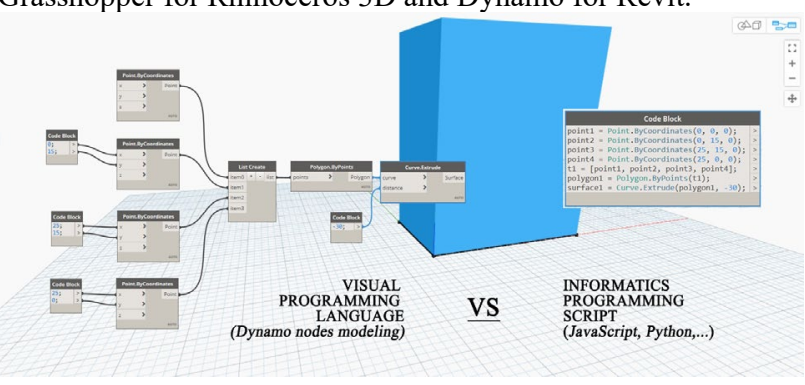

Figure 5. 3D modeling strategy comparison: VPL and programming scripts

In VPL the programming as a written coding process is almost totally replaced by tools that visually connect small blocks, called nodes Figure 5. Each node, referring to main libraries packages, has specific and independent functionality and is inserted into a bigger and hierarchical system of parametric rules. The main use of these tools is usually bounded, in architectural design processes, about generating parametric geometries inside CAD 3D software, but the advent of BIM technologies has allowed it to become increasingly explored (Salamak et al., 2018). Especially in the engineering field, VPL is developed for integrating into 3D parametric models geometric and semantic data and, e.g. data and models for numerical analysis concerning the energetical characteristic improvement of a building (Altun \& Akcamete-Gungor, 2015). Although VPL is now popular in object-based design processes, applications for database management and large-scale threedimensional urban modeling and analysis have yet not been particularly deepen yet.

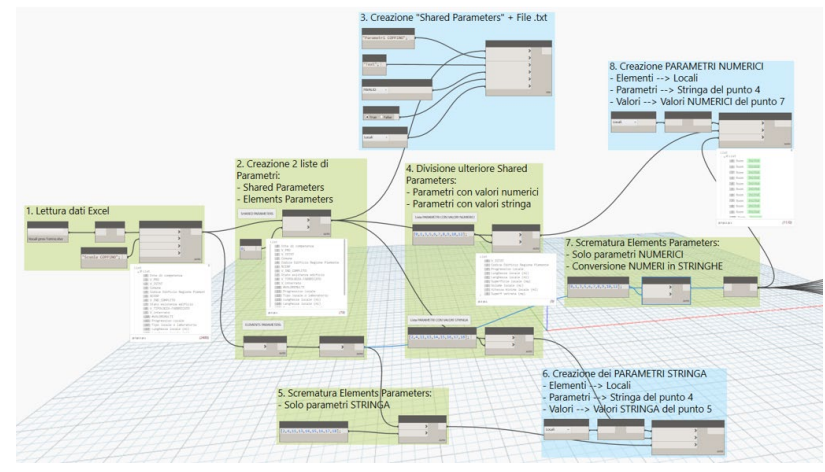

Figure 6. The entire pipeline of Dynamo script related to the EDISCO school database

The Dynamo workflow was set up as in Figure 6 to import alphanumeric datasheets containing numbers of records corresponding to minimum units of analysis, depending on the configuration and origin of specific municipality database: 
- cadastral units for public building assets of Torino municipality

- $\quad$ spaces/rooms for the school building EDISCO database Specifically for dataset (II), $\mathrm{n}^{\circ} 19$ attributes have been defined "parameters" for 130 objects, the rooms of the selected school building (total of 2470 records), the Coppino school.

The rule of nodes allows the creation of shared parameters in text code to be imported into the BIM model, granting the ability to transfer the DB structure into the hierarchy of rooms into the BIM in form of query parameters.

The methodological and operational premise is the relationship based on a unique coding numbering that identifies rooms units in the DB and room spaces in BIM model. As a matter of fact, it is essential to say that in some cases it was necessary to force the correspondence because there was mismatches between the identification of the same room in the two DB.

Besides the integration of the shared parameters inside the BIM environment, it was also possible verify the semantic data transfer through the definition of automated queries and calculation operations. For example, for a query on the room elements: the extraction of each classroom's surface to compare the number of effective scholastics population with the maximum occupancy amount parameter, called by the restrictions caused by the pandemic period.

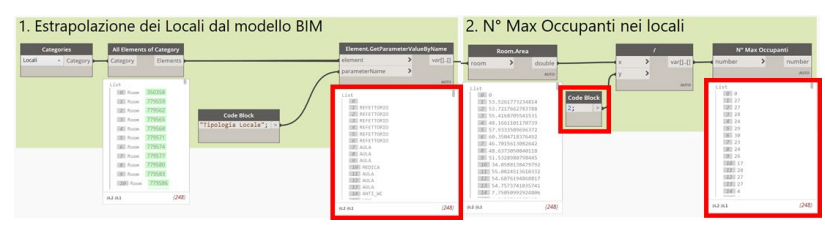

Figure 7. The script for the query focused on school strategic organization: Automatic selection of rooms of the school for calculation of the maximum capacity

\section{RESULTS AND DISCUSSION: BIM-BASED MODELS AUGMENTING 3D DIGITAL TWIN}

It is now important to underline that we'll consider the opportunity to test the two type of BIM models, semantically enriched with DB (I) and (II) and holding different scale data, to be insert into the LOD2 3D city mode of the Torino Municipality. The LOD100-200 parametric object semantically enriched generated from building footprint inheriting the cadastral parcel DB on public building information (see par. 4.1) The LOD 100400 parametric model referring to a complete BIM model (so called construction) generally available for public buildings (see par. 4.1). Several researches have been recently conducted in the direction of defining data model conversion and verification on the integration of BIM-GIS (Barzegar et al., 2021). Further implementation should be conducted in current methodology to monitor the validity of IFC elements and the consistency of parametric objects with semantic information. In this phase such information are essentially referring, once imported into 3D GIS space, to floors- and rooms-related information. For what concerns the importing of the BIM model (originated from Autodesk Revit) in this first workflow test, ESRI ArcGIS Pro has been exploited, thanks to the possibility, from 2019, to directly link the *rvt file inside the GIS environment, maintaining geometry hierarchy and parametric connected information in the form of attribute table. Basically, once the folders related to the BIM models has been created within the GeoDB project, the parametric objects, navigable according to their hierarchy are visible as 3D layer in the project space (Architectural, Mechanical, Electrical, Piping, Structural elements categories can be managed). The main bottlenecks that have been noticed are the georeferencing issues, the non-manageable incoming data formats, their hierarchy, and relations, as well as some issues correlated to the foreseen updating of the original BIM models. For what concerns georeferentiation issue, it represents a big issue for interoperability concerns. It is possible to assign into Revit parametric modeling workflow, the model location by using insertion point $\mathrm{P}=(x, y$, elevation $)$ or exploiting the geographic value of cartographic footprints entities corresponding to LoD0 model, as a base polygon for masses and floors design. Pertaining the data format issue, the BIM hierarchy of objects are loaded as Multipatch Feature Class and BIM semantic parameters are converted into an attribute table (both original and VPLoriginated from public assets DB). These objects are hierarchically divided, as previously specified, but once imported into the GeoDB they lose the semantic relation between themselves at present. Finally, it was tested the automatic capacity of the GIS space of responding to updates operated into the original BIM model, in the idea of planned integrations or updating of geometric or semantic content, and this could represent a future challenge mostly from database programming and advanced computing point of view, due to the remarkable amount of data. In the following discussion below is synthetically organized a presentation of the two preliminary steps for the validation of annotated 3D BIM-based buildings models.

\subsection{BIM model LOD $100-200$ storing real estate parcels data into 3D enabled space}

The parametric approach, if based on the georeferenced building footprint entities could be used to further link the cadastral DB information with the presented VPL pipeline. It will deliver 3D models in LOD 100 (mass, corresponding to LoD2 in GIS model) and LOD200 (floors objects, corresponding as presented (Konde et al., 2018) to a hybrid form of LoD0 according to recent City GML data model implementation) (Figure 8 a). 3D object visualized as Multipatch Feature Class can be managed and queried for floors-related data as in (Figure $8 \mathrm{~b}$ ).

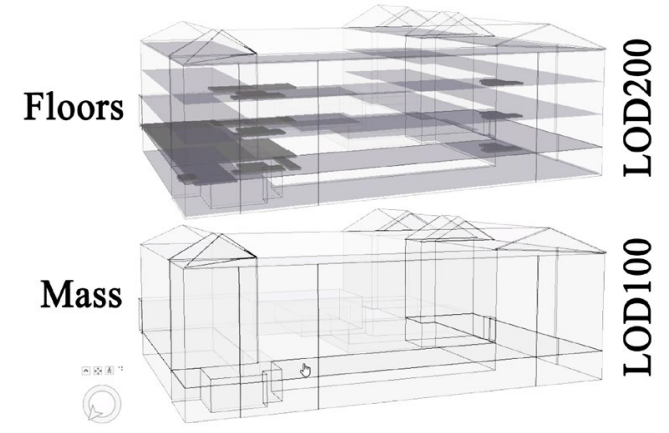

(a)

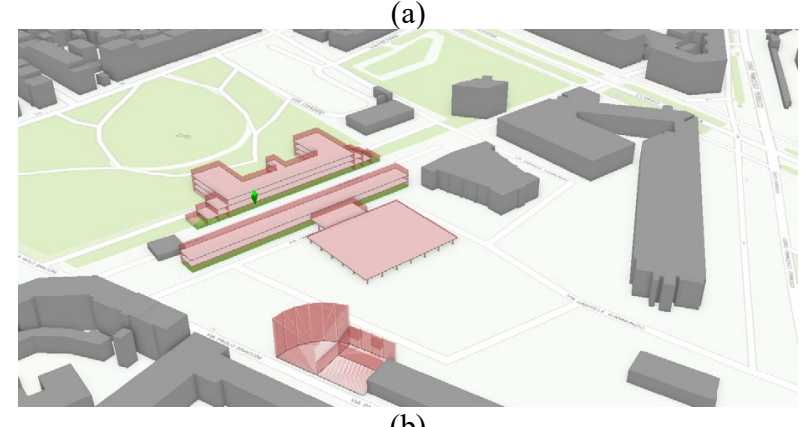

(b)

Figure 8. LOD 200 parametric model visualization and exploration into GIS 3D. 


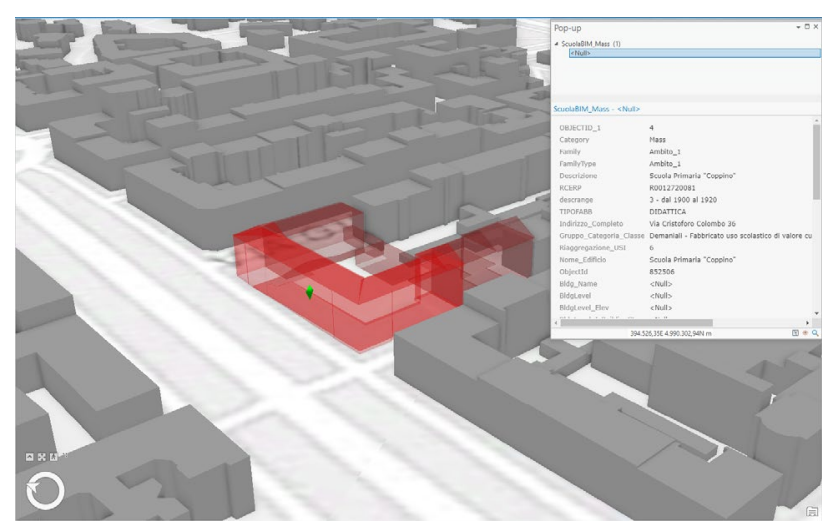

(a) LOD100 mass

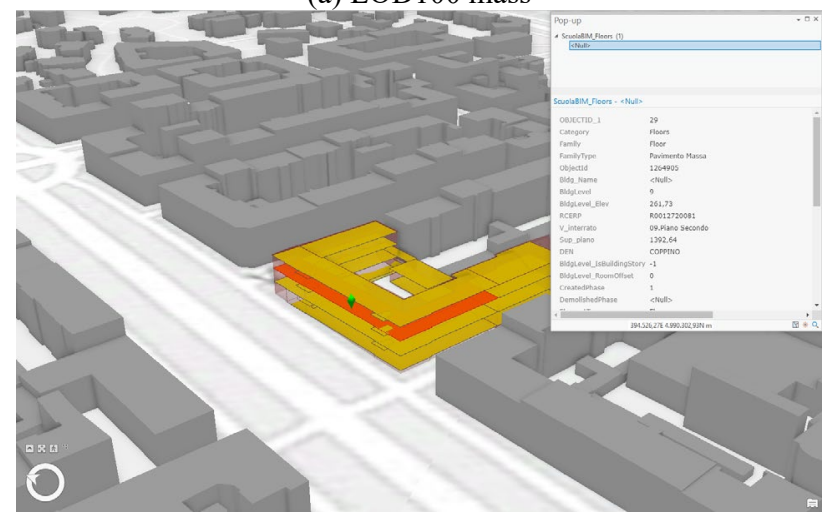

(b) LOD200 floors

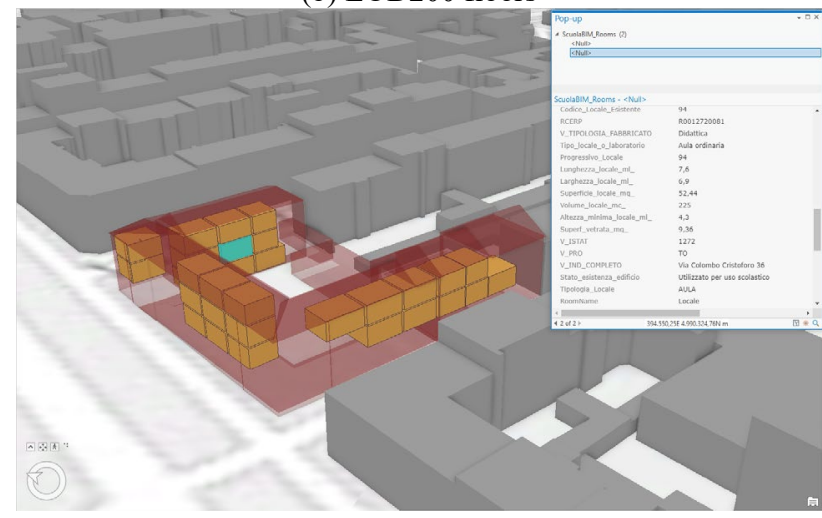

(c) LOD200 rooms

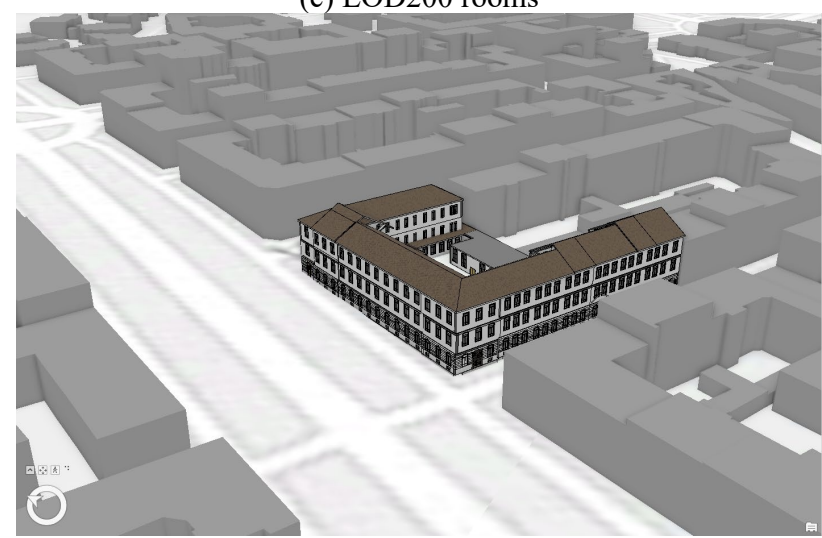

(d) LOD400

Figure 9. The Scuola Coppino multi-scale parametric model migrated into the Digital Twin at different LODs
4.2 BIM model LOD 400 carrying school-related data into 3D enabled space: the Coppino school

Reversing the point of view, if the procedure starts from the availability of a BIM model up to LOD 400 (as the Coppino school), correctly and consistently structured as well as harmonized with the relative database (EDISCO regional database in this case), the results could disclose interesting perspective in multi-scale and multi-content 3D models Figure 9 to be straightforwardly linked in the 3D GIS space, in the perspective of enabling the digital replicas to be effectively twinning the real assets, in an innovative conception of advanced facility management $3 \mathrm{D}$ platform.

\subsubsection{Querying the $3 D$ digital twin}

The parametric objects, as already clarified, due to the nature of their own parametric origin, are manageable for single-queries (Figure 10) related to unique-object exploring, e.g., spatial analysis related to identification of occurrences in the same school building. Nevertheless, if we consider a more complex analysis they must necessarily be transformed into Multipatch Feature Class to be managed and queried exploring the identification of city-scale phenomena related to the schools infrastructures, e.g: the selection of all the high schools with a lecture hall exceeding $100 \mathrm{~m}^{2}$, or the elementary schools they have rooms with internal space surface between $40-50^{2}$.

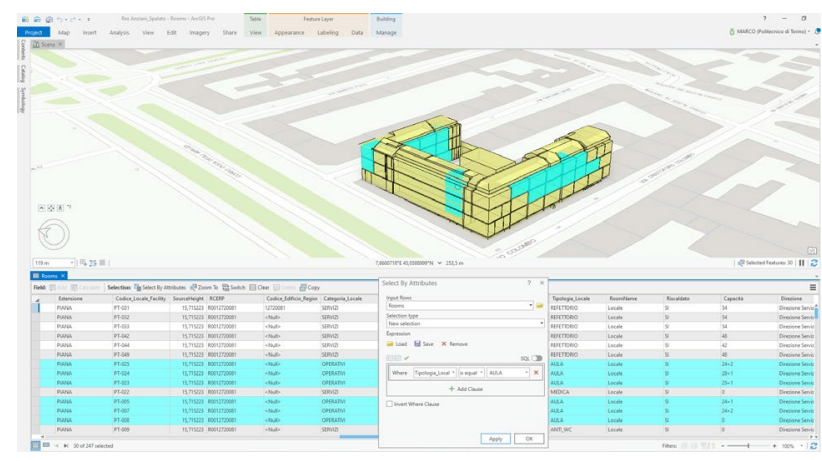

Figure 10. Room entity-based queries performed on different buildings according to EDISCO database on schools buildings BIM model into GeoDB.

\section{CONCLUSION}

The research toward effective interoperability in BIM-to-GIS data management it is far from being achieved. Likewise, the awareness of what it means to operate a digital twinning of the city, and in which directions. The research is in the midst of development. In fact, sometimes it is necessary to descend into the urban policies and management reality, by pursuing and testing operational frameworks adaptable to the needs of public administrations. Facing different databases languages, data schemas and updating, some alternative and parallel paths merging GIS geo-space and BIM modelling rules can be explored, that would be able to exploit the flexibility of the VPL parameterization, as in the present case.

Working in the direction of 2D and 3D data model definition and standardization on databases and coherently establishing relationships among information stored, generally it is possible to contribute to the efforts investment. These should be even more targeted not only to the BIM-GIS workflow conversion only, typically with the aim of enriching the geospatial dimension of the BIM urban models importing them in the geographical databases, but without losing the control of the hierarchy in the semantic architectural content. Further improvements need to be 
focused on many directions. Firstly further exploration on FOSS platforms and data models; then the workflow streamline, to be standard compliant (IFC, CityGML oLoD, iLoD). The reasoning about applicability, generalization and operational behaviour in case of large numbers of objects should be undertaken in next research progress.

\section{ACKNOWLEDGEMENTS}

The research have been conducted with the collaboration of FULL-Future Urban Legacy Lab, Fondazione Agnelli, and Urban Lab with ROCK EU project. Authors would like to thanks people differently involved in the researches and particularly for Città Torino, CSI Piemonte and Regione Piemonte EDISCO department for the databases releases.

\section{REFERENCES}

Altun, M., \& Akcamete-Gungor, A. (2015). BIM-based MultiObjective Building Life Cycle Energy Performance Evaluation Using Particle Swarm Optimization. Proc. of the 32nd CIB W78 Conference 2015, 27th-29th 2015, Eindhoven, The Netherlands.

Baltsavias, E. P. (1999). Airborne laser scanning: Basic relations and formulas. ISPRS Journal of Photogrammetry and Remote Sensing, 54(2-3), 199-214. https://doi.org/10.1016/S09242716(99)00015-5

Barzegar, M., Rajabifard, A., Kalantari, M., \& Atazadeh, B. (2021). An IFC-based database schema for mapping BIM data into a 3D spatially enabled land administration database. International Journal of Digital Earth, 1-30. https://doi.org/10.1080/17538947.2021.1875062

Batty, M. (2018). Digital twins. Environment and Planning B: Urban Analytics and City Science, 45(5), 817-820. https://doi.org/10.1177/2399808318796416

Bauer, P., Stevens, B., \& Hazeleger, W. (2021). A digital twin of Earth for the green transition. In Nature Climate Change (Vol. 11, Issue 2, pp. 80-83). Nature Research. https://doi.org/10.1038/s41558-021-00986-y

Biljecki, F., Ledoux, H., \& Stoter, J. (2016). An improved LOD specification for 3D building models. Computers, Environment $\begin{array}{llll}\text { and } \quad \text { Urban } & \text { Systems, } & \text { 59, }\end{array}$ https://doi.org/10.1016/j.compenvurbsys.2016.04.005

Biljecki, F., Stoter, J., Ledoux, H., Zlatanova, S., \& Çöltekin, A. (2015). Applications of 3D City Models: State of the Art Review. ISPRS International Journal of Geo-Information, 4(4), 2842-2889. https://doi.org/10.3390/ijgi4042842

Billen, R., Cutting-Decelle, A.-F., Marina, O., de Almeida, J.-P., M., C., Falquet, G., Leduc, T., Métral, C., Moreau, G., Perret, J., Rabin, G., San Jose, R., Yatskiv, I., \& Zlatanova, S. (2014). 3D City Models and urban information: Current issues and perspectives. I-118. https://doi.org/10.1051/tu0801/201400001

Boshernitsan, M., Downes, M., \& Downes, M. S. (2004). Visual Programming Languages: A Survey.

DUET project, EU.

https://cordis.europa.eu/project/id/870697/it

(2019).

Eriksson, H., \& Harrie, L. (2021). Versioning of 3D City Models for Municipality Applications: Needs, Obstacles and Recommendations. ISPRS International Journal of GeoInformation, 10(2), 55. https://doi.org/10.3390/ijgi10020055

Hagba, D. V, Gura, D. A., Pyatashova, O. V, Pshidatok, S. K., \& Pavlyukova, A. P. (2021). Improving the Technology for Implementing a 3D Cadastre in Existing Accounting Information Systems. IOP Conference Series: Earth and $\begin{array}{lll}\text { Environmental } & \text { Science, } & \text { 720(1), }\end{array}$ https://doi.org/10.1088/1755-1315/720/1/012030

Jayaraj, P., \& Ramiya, A. M. (2018). 3D CITYGML BUILDING MODELLING FROM LIDAR POINT CLOUD DATA. https://doi.org/10.5194/isprs-archives-XLII-5-175-2018

Konde, A., Tauscher, H., Biljecki, F., \& Crawford, J. (2018). FLOOR PLANS IN CITYGML. ISPRS Annals of Photogrammetry, Remote Sensing and Spatial Information Sciences, IV-4/W6(4/W6), 25-32. https://doi.org/10.5194/isprsannals-IV-4-W6-25-2018

Kutzner, T., Chaturvedi, K., \& Kolbe, T. H. (2020). CityGML 3.0: New Functions Open Up New Applications. PFG - Journal of Photogrammetry, Remote Sensing and Geoinformation Science, 88(1), 43-61. https://doi.org/10.1007/s41064-02000095-z

Lehner, H., \& Dorffner, L. (2020). Digital geoTwin Vienna: Towards a Digital Twin City as Geodata Hub. PFG - Journal of Photogrammetry, Remote Sensing and Geoinformation Science, 88(1), 63-75. https://doi.org/10.1007/s41064-020-00101-4

Lisec, A., Ferlan, M., \& Tekavec, J. (2017). 3D Modelling of a Cadastral Treasure: Towards a 3D Cadastre in Slovenia. GIM International, 31(4), 35-37.

Nex, F., Rupnik, E., \& Remondino, F. (2013). Building Footprints Extraction from Oblique Imagery. ISPRS Annals of Photogrammetry, Remote Sensing and Spatial Information Sciences, II-3/W3, 61-66. https://doi.org/10.5194/isprsannalsII-3-W3-61-2013

Noardo, F., Harrie, L., Arroyo Ohori, K., Biljecki, F., Ellul, C., Krijnen, T., Eriksson, H., Guler, D., Hintz, D., Jadidi, M. A., Pla, M., Sanchez, S., Soini, V.-P., Stouffs, R., Tekavec, J., \& Stoter, J. (2020). Tools for BIM-GIS Integration (IFC Georeferencing and Conversions): Results from the GeoBIM Benchmark 2019. ISPRS International Journal of GeoInformation, 9(9), 502. https://doi.org/10.3390/ijgi9090502

Pfeifer, N., \& I.P.F. Team. (2008). DSM / DTM Filtering. In International School on Lidar Technology. http://home.iitk.ac.in/ blohani/LiDARSchool2008/Downloads/ DTM_pfeifer.pdf

Rottensteiner, F., Sohn, G., Gerke, M., Wegner, J. D., Breitkopf, U., \& Jung, J. (2014). Results of the ISPRS benchmark on urban object detection and 3D building reconstruction. ISPRS Journal of Photogrammetry and Remote Sensing, 93, 256-271. https://doi.org/10.1016/j.isprsjprs.2013.10.004

Ruohomaki, T., Airaksinen, E., Huuska, P., Kesaniemi, O., Martikka, M., \& Suomisto, J. (2018). Smart City Platform Enabling Digital Twin. 2018 International Conference on Intelligent Systems $\quad$ (IS), $155-161$. https://doi.org/10.1109/IS.2018.8710517

Salamak, M., Jasiński, M., Płaszczyk, T., Żarski, M., Jasinski, M., Plaszczyk, T., \& Zarski, M. (2018). Analytical Modelling in Dynamo. Civil Engineering Series. https://doi.org/10.31490/tces-2018-0014

Shahat, E., Hyun, C. T., \& Yeom, C. (2021). City Digital Twin Potentials: A Review and Research Agenda. Sustainability, 13(6), 3386. https://doi.org/10.3390/su13063386

Sithole, G., \& Vosselman, G. (2004). Experimental comparison of filter algorithms for bare-Earth extraction from airborne laser scanning point clouds. ISPRS Journal of Photogrammetry and Remote Sensing, 59(1-2), 85-101. https://doi.org/10.1016/j.isprsjprs.2004.05.004

Tang, L., Li, L., Ying, S., \& Lei, Y. (2018). A Full Level-ofDetail Specification for 3D Building Models Combining Indoor and Outdoor Scenes. ISPRS International Journal of GeoInformation, 7(11), 419. https://doi.org/10.3390/ijgi7110419 